\title{
A PROSPECTIVE MULTI-CENTRIC STUDY ON INCIDENCE OF CONGENITAL ANOMALIES
}

\section{JANGRA $S^{1}$, SHRIVASTAVA $B^{2}$, BHYAN $B^{3}$, MEENA BS ${ }^{4}$ AND HUDA $\mathbf{N}^{5}$}

1: Research Scholar, School of Pharmaceutical Sciences, Jaipur National University, Jaipur

2: Director, School of Pharmaceutical Sciences, Jaipur National University, Jaipur

3: Asst. Professor, Teerthanker Mahaveer College of Pharmacy, Teerthanker Mahaveer University, U.P.

4: Medical Superintendent, Professor \& Unit Head, department of OBG \& Gynaecology, S.M.S. Medical College Jaipur, Rajasthan

5: Additional Professor, Department of Paediatric Orthopaedics, King George's Medical University, Lucknow, Uttar Pradesh

*Corresponding Author: Sarita Jangra: E Mail: sarita28787@gmail.com

Received $28^{\text {th }}$ Dec. 2020; Revised $30^{\text {th }}$ Jan. 2021; Accepted $15^{\text {th }}$ March 2021; Available online $1^{\text {st }}$ Oct. 2021

https://doi.org/10.31032/IJBPAS/2021/10.10.6066

\begin{abstract}
Congenital malformations remain a common cause of prenatal as well as neonatal deaths accounting for $10-15 \%$ in developing countries like India. There are various causes of congenital anomaly. Approximately, $50 \%$ of congenital anomalies cannot be related to a specific cause. Congenital anomalies are important causes of infant and childhood deaths, chronic illness and disability. Congenital anomalies can be structural or developmental. Hence, the present study thus endeavours to find the incidence of congenital anomalies and also assess the frequency of anomalies in various systems. This cross- sectional study was carried out at two multi-speciality hospitals, Rajasthan over a period of more than two years. A complete history of pregnant women and children, laboratory parameters, details of infants and children with congenital anomalies were extracted from their medical records. A total of 500 children including newborns and infants were included based on the inclusion criteria. All the 500 participants were divided equally into two groups namely $\mathrm{A}$ and $\mathrm{B}$ since data were collected at two different hospitals. The overall incidence of anomalies in Group A was $78 \%$ whereas in Group B it was $82 \%$. The higher incidence of
\end{abstract}


Congenital malformation is seen in the musculoskeletal system in Group A and gastrointestinal system in Group B. Congenital malformations are still a burden to address, and the pattern of congenital anomalies varies from centre to centre. Delivering proper antenatal care, regular folic acid supplementation, anomaly scans, counselling women of reproductive age group would help in reducing the incidence of congenital anomalies.

\section{Keywords: Congenital, Anomaly, Incidence, Death, Illness}

\section{INTRODUCTION}

According to the World Health Organization (WHO), congenital anomaly is defined as any morphological, functional, biochemical or molecular defects that may develop in the embryo and fetus from conception until birth, present at birth, whether detected at that time or not. Based on WHO, about 3 million fetuses and infants are born each year with major malformations $[\mathbf{1}, \mathbf{2}]$. The incidence of congenital anomalies has been expanding in the recent past. The worldwide incidence of congenital disorder is estimated around 3$7 \%$, but actual numbers vary widely due to under reporting of cases in developing countries [3]. Congenital anomalies impart long-term disability which may have crucial influence on individuals, families and the society on the whole. Congenital malformations remain a common cause of prenatal as well as neonatal deaths accounting for $10-15 \%$ in developing countries like India [4, 5]. Birth Defects Registry of India (BDRI) was instituted in 2001 by Fetal Care Research Foundation to document incidences of congenital abnormalities in India. A literature search reveals that India has the highest number of children with birth defects [6]. There are various causes of congenital anomaly. Approximately, 50\% of congenital anomalies cannot be related to a specific cause. Nevertheless, known causes include single gene defects, chromosomal disorders, multifactorial inheritance, environmental teratogens and micronutrient deficiencies [7]. Multi-factorial birth defects are caused by a combination of genes and environmental exposures. Congenital anomalies are important causes of infant and childhood deaths, chronic illness and disability. Congenital anomalies can be structural or developmental. A few common structural congenital anomalies include heart defects, spina bifida, a cleft lip or palate, and clubfoot. Developmental issues are not always congenital anomalies. Down syndrome, visual and hearing impairments, cerebral palsy and genetic disorders are some 
familiar developmental congenital anomalies

[8]. Early diagnosis and treatment of all birth defects is of clinical and public health importance. In spite of antenatal diagnostic modality, the fetal autopsy still plays the vital role in the conformation as well as identification of congenital anomalies and also for the counseling of the parents to prevent the fetal congenital anomalies in further pregnancies [9]. A preconception examination otherwise known as a preconception visit is one of the best ways to ensure a healthy pregnancy. The preconception examination includes family medical history, genetic testing, vaccination status and infection screening [10]. Hence, the present study thus endeavours to find the incidence of congenital anomalies and also assess the frequency of anomalies in various systems.

\section{MATERIALS AND METHODS}

\section{Study Design}

This cross- sectional study was carried out at two multi-speciality hospitals, Rajasthan over a period of more than two years. This study was conducted between the period June 2017 and August 2019. People with the following criteria were allowed to participate in this study: a) Children factors includes 0 to 3 years of children having congenital malformations, both male and female children; b) Maternal factors includes mother had a risk factor of parity, history of maternal illness, pre-eclampsia and eclampsia, smoking and alcohol consumption, pregnancy history of breech presentation, vaginal bleeding, gestational period and previous abortion or stillbirth, deficiency of multivitamins and folic acid, intake of any drug; c) Pregnant mother observed from starting of the gestation period till delivery. The following criteria were excluded: a) Paternal genetic factors; b) Children above 3 years.

\section{Data Collection}

People who meet the inclusion criteria were enrolled for the study. Informed consent was obtained from the subject or attenders of the subject. A complete history of pregnant women and children, laboratory parameters associated with a specific disease in pregnancy, details of infants and children with congenital anomalies were extracted from their medical records with the support of consultants and documented in a suitably designed individual case record form.

\section{Statistical Analysis}

Statistical analyses were performed using Microsoft Excel and Statistical Package for Social Service (SPSS) Version 20. Categorical data are presented as numbers and percentages. Chi-square test was carried 
out for the analysis of categorical variables. $\mathrm{P}$ value less than 0.05 were considered statistically significant at $5 \%$ level of significance with a confidence interval of $95 \%$.

\section{RESULTS}

During the study period, a total of 500 children including newborns and infants were included based on the inclusion criteria. All the 500 participants were divided equally into two groups namely A and B since data were collected at two different hospitals. Each group consists of 250 participants, which is shown in Table 1 and Figure 1. The overall incidence of anomalies in Group A was $78 \%$ whereas in Group B it was $82 \%$. The $\mathrm{P}$ value of 0.2170 indicated that significant difference was not seen in the distribution of anomaly between two groups.
Incidence of anomalies of various systems in each group has been shown in Table 2 and Figure 2. The higher incidence of Congenital malformation is seen in the musculoskeletal system in Group A and gastrointestinal system in Group B. The lowest incidence is seen in the otolaryngological system in Group A and genital, renal and vascular system in Group B. The $\mathrm{P}$ value of $<0.05$ indicated that significant difference is seen in the distribution of system-wise anomalies between Group A and Group B. Difference is observed in the anomalies of musculoskeletal, dermatological, gastrointestinal and genital system. The comprehensive list of anomalies seen in various systems were given in Table $\mathbf{3 a}, \mathbf{3 b}$ \& 3c.

Table 1: Group Distribution with incidence of anomalies

\begin{tabular}{|c|c|c|c|}
\hline Group & $\mathrm{N}=\mathbf{5 0 0}$ & Anomaly & P value \\
\hline $\mathbf{A}$ & $250(50)$ & $195(78)$ & \\
\hline B & $250(50)$ & $206(82)$ & 0.2170 \\
\hline
\end{tabular}

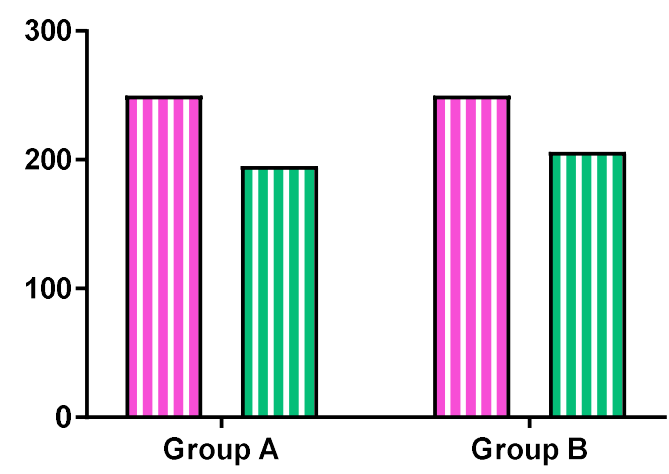

Figure 1: Group Distribution with incidence of anomalies 
Table 2: Incidence of anomalies of various systems in population of Group A and Group B

\begin{tabular}{|c|c|c|c|c|c|c|}
\hline \multirow{2}{*}{ S. No } & \multirow{2}{*}{ Name of the System } & \multicolumn{2}{|c|}{ Group A } & \multicolumn{2}{|c|}{ Group B } & \multirow{2}{*}{$P$ value } \\
\hline & & $\mathbf{N}$ & $\%$ & $\mathbf{N}$ & $\%$ & \\
\hline 1 & Cardiovascular system & 11 & 06 & 13 & 06 & 0.7775 \\
\hline 2 & Craniospinal anomalies & 18 & 09 & 26 & 13 & 0.2776 \\
\hline 3 & Ophthalmology anomalies & 12 & 06 & 06 & $\mathbf{0 3}$ & 0.1172 \\
\hline 4 & Musculoskeletal anomalies & 62 & 32 & 24 & 12 & $<0.0001$ \\
\hline 5 & Dental anomalies & 03 & 02 & 00 & $\mathbf{0}$ & 0.0739 \\
\hline 6 & Otolaryngological (ENT) anomalies & $\mathbf{0 2}$ & 01 & 05 & $\mathbf{0 2}$ & 0.2841 \\
\hline 7 & Anomalies of genetic disorders & 04 & $\mathbf{0 2}$ & $\mathbf{0 2}$ & 01 & 0.3731 \\
\hline 8 & Renal anomalies & 18 & 09 & $\mathbf{0 2}$ & 01 & 0.0001 \\
\hline 9 & Dermatological anomalies & 35 & 18 & 07 & $\mathbf{0 3}$ & $<0.0001$ \\
\hline 10 & Gastrointestinal anomalies & 13 & 06 & 71 & 35 & $<0.0001$ \\
\hline 11 & Facial anomalies & 14 & 07 & 21 & 10 & 0.2851 \\
\hline 12 & Anomalies of genital system & $\mathbf{0 3}$ & $\mathbf{0 2}$ & 26 & 13 & $<0.0001$ \\
\hline 13 & Vascular malformation & $\mathbf{0}$ & $\mathbf{0}$ & $\mathbf{0 3}$ & 01 & 0.0907 \\
\hline
\end{tabular}

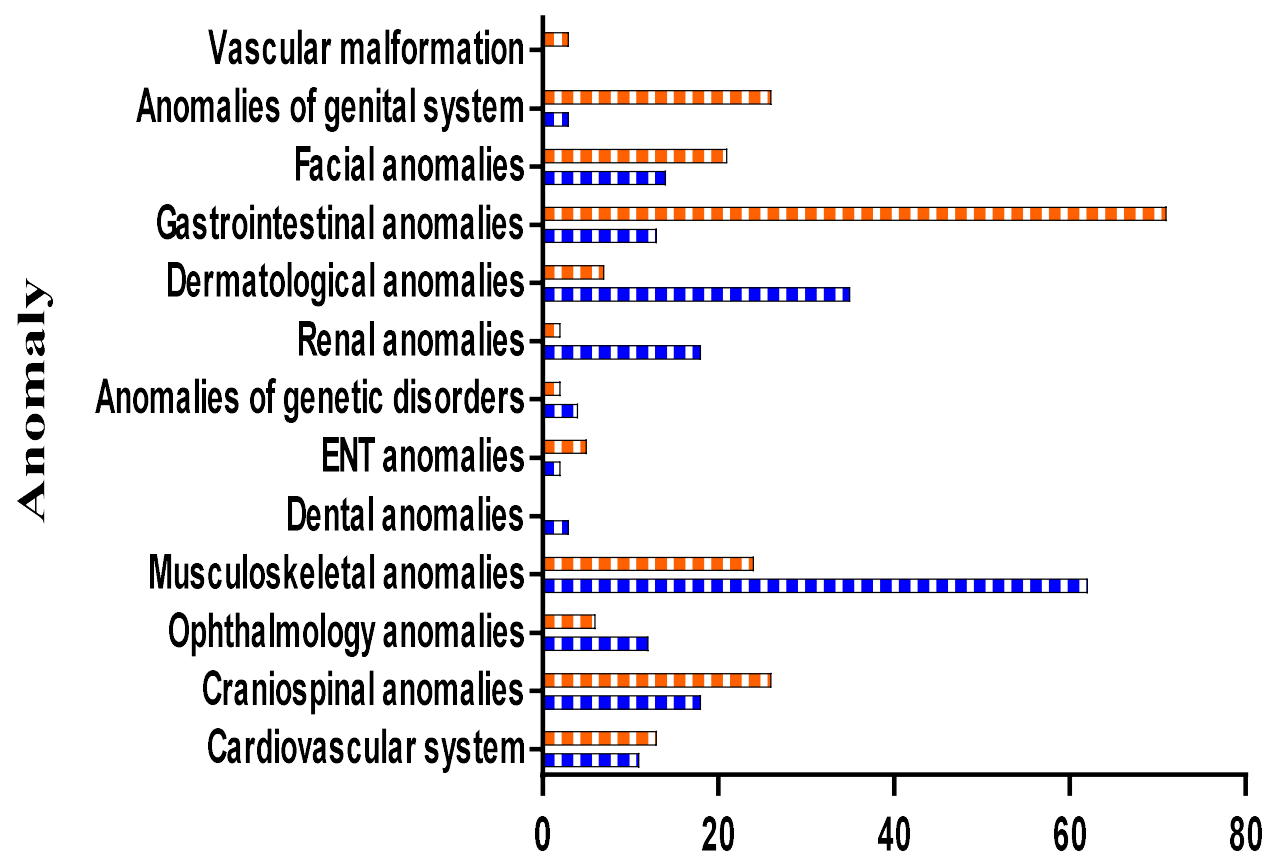

Figure 2: Incidence of anomalies of various systems in population of Group A and Group B 
Table 3a: List of Cardiovascular, Craniospinal, Ophthalmological, Dental \& ENT Anomalies

\begin{tabular}{|c|c|c|c|c|c|}
\hline \multirow{2}{*}{$\begin{array}{c}\text { S. } \\
\text { No } \\
\end{array}$} & \multirow{2}{*}{ System } & \multicolumn{2}{|c|}{ Group A } & \multicolumn{2}{|c|}{ Group B } \\
\hline & & $\mathbf{N}$ & $\%$ & $\mathbf{N}$ & $\%$ \\
\hline \multirow{5}{*}{1} & \multicolumn{5}{|l|}{ Cardiovascular System } \\
\hline & Atrial Septal Defect & 4 & 2 & 2 & 1 \\
\hline & Ventricular Septal Defect & 5 & 3 & 5 & 2 \\
\hline & Tetralogy of Fallot'S & 1 & 0.5 & 4 & 2 \\
\hline & Transposition fo great vessels with Atrial Septal Defect & 1 & 0.5 & 2 & 1 \\
\hline \multirow{10}{*}{2} & \multicolumn{5}{|l|}{ Craniospinal System } \\
\hline & Foetal Hydrocephalous with Cervical Meningocele & 10 & 5 & 6 & 3 \\
\hline & Occipital Encephalocele with Rachischisis & 1 & 0.5 & 3 & 1.5 \\
\hline & Cranio - Rochischisis - Open Spina Bifida & 1 & 0.5 & 1 & 0.5 \\
\hline & Lumbar Meningomyelocele with Hydrocephalous & 1 & 0.5 & 8 & 4 \\
\hline & Anencephaly & 1 & 0.5 & 3 & $\mathbf{1 . 5}$ \\
\hline & Cervical Meningocele & 1 & 0.5 & 1 & 0.5 \\
\hline & Arnold Chiary Syndrome of Type-II & 1 & 0.5 & $\mathbf{0}$ & $\mathbf{0}$ \\
\hline & Hydraencephaly & 1 & 0.5 & $\mathbf{0}$ & $\mathbf{0}$ \\
\hline & Lumbar Meningocele & 1 & 0.5 & 4 & 2 \\
\hline \multirow{8}{*}{3} & \multicolumn{5}{|l|}{ Ophthalmological Anomalies } \\
\hline & Aniridia & 5 & 3 & $\mathbf{0}$ & $\mathbf{0}$ \\
\hline & Iris Coloboma & 4 & 2 & $\mathbf{0}$ & $\mathbf{0}$ \\
\hline & Irido Lentomacular Coloboma & 1 & 0.5 & $\mathbf{0}$ & $\mathbf{0}$ \\
\hline & Retinal Colloidal Coloboma & 1 & 0.5 & $\mathbf{0}$ & $\mathbf{0}$ \\
\hline & Iridio Corneal Endothelial Syndrome & 1 & 0.5 & $\mathbf{0}$ & $\mathbf{0}$ \\
\hline & Anophtholmos & $\mathbf{0}$ & $\mathbf{0}$ & 3 & 1.5 \\
\hline & Exophtholmos & $\mathbf{0}$ & $\mathbf{0}$ & 1 & 0.5 \\
\hline \multirow{3}{*}{4} & \multicolumn{5}{|l|}{ Dental Anomalies } \\
\hline & Hereditary Ectodermal Dysplasia with multiple absence of Teeth & 1 & 0.5 & $\mathbf{0}$ & $\mathbf{0}$ \\
\hline & Hereditary Ectodermal Dysplasia & 1 & 0.5 & $\mathbf{0}$ & $\mathbf{0}$ \\
\hline \multirow{4}{*}{5} & \multicolumn{5}{|l|}{ Otolaryngological (Ent) Anomalies } \\
\hline & $\begin{array}{l}\text { A) Absence of External Auditory Meatus B) Few Auditory Buds with absence of } \\
\text { Auditory Canal }\end{array}$ & 1 & 0.5 & $\mathbf{0}$ & $\mathbf{0}$ \\
\hline & Microtia with External Auditory Canal Atresia & 1 & 0.5 & $\mathbf{0}$ & $\mathbf{0}$ \\
\hline & Congenital absence of Naso Lacrimal Duct & $\mathbf{0}$ & $\mathbf{0}$ & 3 & 1.5 \\
\hline
\end{tabular}


Table 3b: List of Musculo skeletal, Dermatological and Facial Anomalies

\begin{tabular}{|c|c|c|c|c|c|}
\hline \multirow{2}{*}{ S. No } & \multirow{2}{*}{ System } & \multicolumn{2}{|c|}{ Group A } & \multicolumn{2}{|c|}{ Group B } \\
\hline & & $\mathbf{N}$ & $\%$ & $\mathbf{N}$ & $\%$ \\
\hline \multirow{13}{*}{1} & \multicolumn{5}{|l|}{ Musculo Skeletal Anomalies } \\
\hline & Congenital Talipes Equino Varus & 15 & 8 & 12 & 6 \\
\hline & Hemi Vertebra at the level of first Thoracic Vertebra & 2 & 1 & $\mathbf{0}$ & $\mathbf{0}$ \\
\hline & Syndactyly & 1 & 0.5 & 2 & 1 \\
\hline & Polydactyly & 2 & 1 & 10 & 5 \\
\hline & Absence of ring and index fingers of Right Upper Limb & 1 & 0.5 & $\mathbf{0}$ & $\mathbf{0}$ \\
\hline & Hammer Toe & 1 & 0.5 & $\mathbf{0}$ & $\mathbf{0}$ \\
\hline & Amnionic Band & 1 & 0.5 & $\mathbf{0}$ & $\mathbf{0}$ \\
\hline & Post Axial Hemi Hypertrophy of in right thumb and index fingers & 1 & 0.5 & $\mathbf{0}$ & $\mathbf{0}$ \\
\hline & Bilateral Polydactyly of the upper limbs & 1 & 0.5 & $\mathbf{0}$ & $\mathbf{0}$ \\
\hline & Absence of Radius on the right side with Single Umbilical Artery & 1 & 0.5 & $\mathbf{0}$ & $\mathbf{0}$ \\
\hline & Congenital Bilateral Polydactyly of both upper and lower limb & 3 & 1.5 & $\mathbf{0}$ & $\mathbf{0}$ \\
\hline & Congenital Developmental Dysplasia of the hip & 20 & 10 & $\mathbf{0}$ & $\mathbf{0}$ \\
\hline \multirow{13}{*}{2} & \multicolumn{5}{|l|}{ Dermatological Anomalies } \\
\hline & Albinism & 1 & 0.5 & $\mathbf{0}$ & $\mathbf{0}$ \\
\hline & Harlequin Baby & 1 & 0.5 & $\mathbf{0}$ & $\mathbf{0}$ \\
\hline & Congenital Melanocyte Naevus & 1 & 0.5 & $\mathbf{0}$ & $\mathbf{0}$ \\
\hline & Non Bullous Icthyosiform Erythroderma & 1 & 0.5 & $\mathbf{0}$ & $\mathbf{0}$ \\
\hline & Ichthyosis Vulgaris & 12 & 6 & $\mathbf{0}$ & $\mathbf{0}$ \\
\hline & Tuberous Sclerosis & 10 & 5 & $\mathbf{0}$ & $\mathbf{0}$ \\
\hline & Xeroderma Pigamentosa & 2 & 1 & $\mathbf{0}$ & $\mathbf{0}$ \\
\hline & A Port Wine Tumor & 1 & 0.5 & $\mathbf{0}$ & $\mathbf{0}$ \\
\hline & Naevus Anaemicus & 6 & 3 & $\mathbf{0}$ & $\mathbf{0}$ \\
\hline & Neuro Fibromatosis & $\mathbf{0}$ & $\mathbf{0}$ & 2 & 1 \\
\hline & Tuberous Sclerosis Complex & $\mathbf{0}$ & $\mathbf{0}$ & 4 & 2 \\
\hline & Xeroderma Pigmantosa with Linear Epidermalnaevus & $\mathbf{0}$ & $\mathbf{0}$ & 1 & $\mathbf{0 . 5}$ \\
\hline \multirow{4}{*}{3} & \multicolumn{5}{|l|}{ Facial Anomalies } \\
\hline & Unilateral Hare Lip & 4 & 2 & $\mathbf{0}$ & $\mathbf{0}$ \\
\hline & Cleft Lip & 6 & 3 & 8 & 4 \\
\hline & Cleft Palate & 4 & 2 & 7 & 3 \\
\hline
\end{tabular}


Table 3c: List of Vascular, Renal, Gastro intestinal, Genetic and Genital Anomalies

\begin{tabular}{|c|c|c|c|c|c|}
\hline \multirow{2}{*}{ S. No } & \multirow{2}{*}{ System } & \multicolumn{2}{|c|}{ Group A } & \multicolumn{2}{|c|}{ Group B } \\
\hline & & $\mathbf{N}$ & $\%$ & $\mathbf{N}$ & $\%$ \\
\hline \multirow{3}{*}{1} & \multicolumn{5}{|c|}{ Vascular Malformation } \\
\hline & Haemangiomas & 1 & 0.5 & $\mathbf{0}$ & $\mathbf{0}$ \\
\hline & Cirsoid Aneurysm & $\mathbf{0}$ & $\mathbf{0}$ & 1 & 0.5 \\
\hline \multirow{7}{*}{2} & \multicolumn{5}{|l|}{ Renal Anomalies } \\
\hline & Foetal Hydronephrois & 2 & 1 & $\mathbf{0}$ & $\mathbf{0}$ \\
\hline & Absence or Agenesis of Right Kidney & 2 & 1 & $\mathbf{0}$ & $\mathbf{0}$ \\
\hline & Ectopic of Right Kidney or Agenesis & 1 & 0.5 & $\mathbf{0}$ & $\mathbf{0}$ \\
\hline & Bilateral Enlarged Echogenic Kidney & 1 & 0.5 & $\mathbf{0}$ & $\mathbf{0}$ \\
\hline & Congenital Nodular Kidney & 1 & 0.5 & $\mathbf{0}$ & $\mathbf{0}$ \\
\hline & Ureterocele & $\mathbf{0}$ & $\mathbf{0}$ & 1 & 0.5 \\
\hline \multirow{15}{*}{3} & \multicolumn{5}{|c|}{ Gastro Intestinal Anomalies } \\
\hline & Atresia of Jejunum associated with dilated stomach & 1 & 0.5 & $\mathbf{0}$ & $\mathbf{0}$ \\
\hline & Absence of Anterior Abdominal wall with Omphalocele & 1 & 0.5 & 4 & 2 \\
\hline & Imperforate Anus & 1 & 0.5 & 11 & 5 \\
\hline & Gastroschsis & 1 & 0.5 & 3 & 1.5 \\
\hline & Mesenteric Cyst & 1 & 0.5 & 2 & 1 \\
\hline & Megacolon & 1 & 0.5 & 15 & 7 \\
\hline & Patent Vitello Intestinal Duct & $\mathbf{0}$ & $\mathbf{0}$ & 1 & 0.5 \\
\hline & Rectal Anomalies & $\mathbf{0}$ & $\mathbf{0}$ & 5 & 2 \\
\hline & Congenital Pyloric Stenosis & 3 & 1.5 & 4 & 2 \\
\hline & Congenital Diaphragmmatic Hernia & $\mathbf{0}$ & $\mathbf{0}$ & 4 & 2 \\
\hline & Omphalocele & 1 & 0.5 & 2 & 1 \\
\hline & Umbilical Hernia & $\mathbf{0}$ & $\mathbf{0}$ & 10 & 5 \\
\hline & Tracheo Oesophageal Fistula & $\mathbf{0}$ & $\mathbf{0}$ & 2 & 1 \\
\hline & Duodenal Atresia & $\mathbf{0}$ & $\mathbf{0}$ & 2 & 1 \\
\hline \multirow{5}{*}{4} & \multicolumn{5}{|c|}{ Anomalies of Genetic Disorders } \\
\hline & Rubinstein Taybi Syndrome & 1 & 0.5 & $\mathbf{0}$ & $\mathbf{0}$ \\
\hline & Translocation of Down's Syndrome & 1 & 0.5 & $\mathbf{0}$ & $\mathbf{0}$ \\
\hline & Trisomy -18-Edward Syndrome & 1 & 0.5 & $\mathbf{0}$ & $\mathbf{0}$ \\
\hline & Down's Syndrome & 1 & 0.5 & 2 & 1 \\
\hline \multirow{5}{*}{5} & \multicolumn{5}{|c|}{ Genital System Anomalies } \\
\hline & Undescended Testes & 1 & 0.5 & 7 & 3 \\
\hline & Phimosis & 11 & 6 & $\mathbf{0}$ & $\mathbf{0}$ \\
\hline & Micro Penis & $\mathbf{0}$ & $\mathbf{0}$ & 1 & 0.5 \\
\hline & Hypospadias & 1 & 0.5 & 4 & 2 \\
\hline
\end{tabular}




\section{DISCUSSION}

The congenital anomalies may occur in one system or may involve multiple systems of the body. They may appear immediately after birth like congenital heart disease or may appear in later part of life which can be detected by the signs and symptoms [11]. In this cross- sectional study, the proportion of congenital anomaly seen is $80 \%$. The commonly involved systems are the central nervous system, cardiovascular system, gastro intestinal systems, integument anomalies, musculoskeletal systems, urinary system anomalies and limb anomalies, disorder of metabolism anomalies, neural tube defects, dental anomalies and genetic disorders like Down's syndrome, genital system anomalies [12]. The studies on anomalies by various workers in India and abroad have shown higher incidences in one of the above systems.

In our study, the maximum number of congenital anomalies was from the musculoskeletal system and the gastro intestinal system followed by dermatological, genital and craniospinal anomalies which is comparable to the study conducted by Bhat et al [13]. Other studies have shown musculoskeletal system was the most common anomalies in live births as followed by gastrointestinal system and defects in the central nervous system seen in still births. The true incidence of congenital anomalies depends upon several factors which includes ethnic background, study population enrolled from hospital or community based, live birth or total birth, nature of study i.e., prospective or retrospective, age at the time of diagnosis, duration of the study period, definition of congenital malformation and the method of their classification, autopsy rate, diagnostic facility available and enthusiasm and acuteness of physician [14]. Congenital developmental dysplasia of the hip and congenital talipes equinovarus were the commonest musculoskeletal anomalies noticed in this study which accounts for $10 \%$, $8 \%$ and $6 \%$.

Globally, congenital anomalies may affect the upper gastrointestinal tract which includes anomalies of the oesophagus, stomach and duodenum. With regard to the gastro intestinal anomalies in our study, megacolon followed by imperforate anus and umbilical hernia were commonly seen, which is similar to the findings reported by Paneer Selvam et al [15]. In our study, the majority of dermatological anomalies were ichthysois vulgaris and tuberous sclerosis. Cleft lip, cleft palate and unilateral hare lip were familiar facial anomalies observed in this study. These findings coincide with the study 
reported by Gandhi et al. The sensitivity for detection of facial clefts remains poor despite the advancement of sonographic technology. Foetal palate is an important finding in determining the requirement for surgery, audiology and orthodontic services into teenage years [16].

Atrial septal defect, ventricular septal defect and tetralogy of fallot were the common type of anomalies seen in the cardiovascular system. In the central nervous system, meningocele and meningomyelocele accounted for $6 \%$ and $8 \%$ which is comparable to the study reported by Bhatia et al [17]. In relation to anomalies of other systems noticed in this study, aniridia followed by anophthalmos in ophthalmology, ectodermal dysplasia in dental, congenital absence of nasolacrimal duct in otolaryngology, hemangioma followed by cirsoid aneurysm in vascular system, foetal hydronephrosis followed by ureterocele in renal, down's syndrome in genetic disorder and phimosis, undescended testes followed by hypospadias in genital system. Despite having high incidence of congenital malformations, there are no proper preventive measures in developing countries like India. This study strongly recommends follow-up in studying the status of babies with birth defects and also brings forth the need for standard guidelines and policies at the national level. The only drawback of our study is small sample size, in spite of it being a two-year study. Our study population could not be representative of the general population due to the above factor.

\section{CONCLUSION}

Congenital malformations are still a burden to address, and the pattern of congenital anomalies varies from centre to centre. It is considered to be an important cause of neonatal morbidity and mortality across the world. The present study highlighted that musculoskeletal and gastrointestinal systems were to be the most commonly affected by congenital malformations. The formulation and implementation of screening protocols which facilitate early identification and treatment of congenital anomalies depend on burden and pattern of the anomaly. Antenatal diagnosis, genetic counselling, better diagnostic and management facilities should be provided to improve the outcome anomalies as well as to reduce the overall incidence of these malformations. Large multi-centric studies are needed to support these findings. In addition, delivering proper antenatal care, regular folic acid supplementation, anomaly scans, counselling women of reproductive age group would help 
in reducing the incidence of congenital anomalies.

\section{ACKNOWLEDGEMENT}

We would like to thank Prof. Birendra Shrivastava -Director and my supervision from Jaipur National University for their invaluable help in the preparation of this manuscript.

\section{DISCLOSURE}

The authors report no conflicts of interest in this work.

\section{BIBLIOGRAPHY}

[1] DeSilva M, Munoz FM, Mcmillan M, et al. Congenital anomalies: Case definition and guidelines for data collection, analysis, and presentation of immunization safety data. Vaccine. 2016; 34(49): 6015-26.

[2] Smith WD. Classification, nomenclature, and naming of morphologic defects. J Pediatr. 1975; 87(1): 162-3.

[3] Bhide P, Gund P, Kar A. Prevalence of Congenital Anomalies in an Indian Maternal Cohort: Healthcare, Prevention, and Surveillance Implications. PLoS One. 2016; 11(11): e0166408.

[4] Ajao AE, Adeoye IA. Prevalence, risk factors and outcome of congenital anomalies among neonatal admissions in OGBOMOSO, Nigeria. BMC Pediatr. 2019; 19(1): 88.

[5] Penchaszadeh VB. Preventing congenital anomalies in developing countries. Community Genet. 2002; 5(1): 61-9.

[6] Sharma R. Birth defects in India: Hidden truth, need for urgent attention. Indian J Hum Genet. 2013; 19(2): 125-129.

[7] El Koumi MA, Al Banna EA, Lebda I. Pattern of congenital anomalies in newborn: a hospital-based study. Pediatr Rep. 2013; 5(1): e5.

[8] Feldkamp ML, Carey JC, Byrne JLB, Krikov S, Botto LD. Etiology and clinical presentation of birth defects: population based study. BMJ. 2017; 357: j2249.

[9] Todros T, Capuzzo E, Gaglioti P. Prenatal diagnosis of congenital anomalies. Images Paediatr Cardiol. 2001; 3(2): 3-18.

[10] Khan NN, Boyle JA, Lang AY, Harrison CL. Preconception Health Attitudes and Behaviours of Women: A Qualitative Investigation. Nutrients. 2019; 11(7): 1490. 
[11] Corsello G, Giuffre M. Congenital malformations. J Matern Fetal Neonatal Med. 2012; 25(1): 25-9.

[12] Rodriguez MM. Congenital Anomalies of the Kidney and the Urinary Tract (CAKUT). Fetal Pediatr Pathol. 2014; 33(5-6): 293320.

[13] Bhat BV, Babu L. Congenital malformations at birth: a prospective study from South India. Indian J Pediatr.1998; 65: 873-81.

[14] Bhide P, Kar A. A national estimate of the birth prevalence of congenital anomalies in India: systematic review and meta-analysis. BMC Pediatr. 2018; 18(1): 175.

[15] Pannerselvam M, Harikrishnan E, Karthick E. Profile of congenital surgical anomalies among admitted neonates - A retrospective study from a rural tertiary care centre, South India. JMSCR. 2019; 7(3): 174-80.

[16] Gandhi MK et al. A study on incidence of congenital anomalies in new borns and their association with fetal factors: a prospective study. Int J Res Med Sci. 2016; 4(4): 1200-3.

[17] Bhatia R, Bhatia G. Spectrum of congenital malformations at birth among neonates in a private medical college in South Rajasthan. Int $\mathbf{J}$ Contemp Pediatr. 2019; 6(5): 20537. 